\title{
Clinical Significance of Exercise Pulmonary Hypertension in Secondary Mitral Regurgitation
}

\author{
Patrizio Lancellotti, MD, $\mathrm{PhD}^{\mathrm{a}, \mathrm{b}, *}$, Julien Magne, $\mathrm{PhD}^{\mathrm{a}}$, Raluca Dulgheru, MD ${ }^{\mathrm{a}}$, Arnaud Ancion, MD , \\ Christophe Martinez, MD ${ }^{\mathrm{a}}$, and Luc A. Piérard, MD, $\mathrm{PhD}^{\mathrm{a}}$
}

\begin{abstract}
In patients with heart failure, exercise echocardiography can help in risk stratification and decision making. The prognostic significance of exercise pulmonary hypertension $(\mathrm{PH})$ in patients with secondary mitral regurgitation (MR) remains unknown. The aim of the present study was to assess the prognostic value of exercise $\mathrm{PH}$ in patients with secondary MR and narrow QRS intervals. From 2005 to 2012, 159 consecutive patients with secondary MR, narrow QRS intervals, left ventricular dysfunction (mean ejection fraction $36 \pm 7 \%$ ), and measurable systolic pulmonary arterial pressure (SPAP) during exercise echocardiography were included. Resting and exercise $\mathrm{PH}$ were defined as SPAP $>50$ and $>60 \mathrm{~mm} \mathrm{Hg}$, respectively. Exercise PH was more frequent than resting PH (40\% vs 13\%, p <0.0001). On multivariate logistic regression, the independent determinants of exercise $\mathrm{PH}$ were resting SPAP $(p<0.0001)$, exercise MR severity $(p<0.0001)$, and $e^{\prime}$-wave velocity $(p=0.004)$. The incidence of cardiac events during follow-up was significantly higher in patients with exercise PH compared with those without exercise PH (4 years: $40 \pm 7 \%$ vs $20 \pm 5 \%$, p <0.0001). Patients with exercise PH exhibited higher rates of cardiac events and death than those with resting $\mathrm{PH}$. In a multivariate Cox proportional hazards model, exercise $\mathbf{P H}$ was independently associated with the occurrence of cardiac events $(p<0.0001)$. In conclusion, in patients with secondary MR, exercise $\mathrm{PH}$ is determined mainly by resting SPAP, left ventricular diastolic burden, and exercise MR severity. Exercise PH is a powerful predictor of poor outcomes, with a 5.3-fold increased risk for cardiac-related death during follow-up. These results highlight the added value of exercise echocardiography in secondary MR. (c) 2015 Elsevier Inc. All rights reserved. (Am J Cardiol 2015; $₫:--\square)$
\end{abstract}

In asymptomatic valvular heart disease, exercise pulmonary hypertension $(\mathrm{PH})$ was recently identified by our group as a powerful marker of advanced risk for cardiac events. ${ }^{1,2}$ In secondary mitral regurgitation (MR), exercise systolic pulmonary arterial pressure (SPAP) is determined mainly by dynamic $\mathrm{MR}^{3}$ and is involved in the pathogenesis of acute pulmonary edema. ${ }^{4}$ The most recent guidelines recommend mitral valve surgery in asymptomatic patients with preserved left ventricular (LV) ejection fractions and severe primary MR, in the presence of exercise PH (a European Society of Cardiology class IIb indication ${ }^{5}$ ). There is no overt indication for surgery in patients with secondary MR and exercise PH, but the European Society of Cardiology guidelines state that exercise PH might be an additional motivation to perform surgery in patients with moderate MR who undergo coronary artery bypass graft surgery (level of evidence C). Nevertheless, the prognostic significance of exercise $\mathrm{PH}$ in patients with secondary MR remains unknown. The aim of the present study was to assess the prognostic value of exercise PH

\footnotetext{
${ }^{\mathrm{a}}$ Department of Cardiology, GIGA Cardiovascular Sciences, Heart Valve Clinic, University Hospital Sart Tilman, University of Liège Hospital, Liège, Belgium; ' $\mathrm{GVM}$ Care and Research, E.S. Health Science Foundation, Lugo (RA), Italy. Manuscript received November 21, 2014; revised manuscript received and accepted February 11, 2015.

Drs. Lancellotti and Magne contributed equally to this work and should be considered joint first authors.

See page 7 for disclosure information.

*Corresponding author: Tel: 003243667194; fax: 003243667195.

E-mail address: plancellotti@chu.ulg.ac.be (P. Lancellotti).
}

in patients with secondary MR. We hypothesized that exercise $\mathrm{PH}$ is an independent predictor of the occurrence of acute pulmonary edema, cardiac events, and mortality.

\section{Methods}

From 2005 to 2012, any patients with secondary MR and chronic LV systolic dysfunction (LV ejection fraction $<45 \%$ ) referred to our heart valve clinic to undergo exercise stress echocardiography were screened for ischemia, exercise tolerance, and dynamic hemodynamic alterations (increase in MR severity, $\mathrm{PH}$, increase in LV filling pressures $)(\mathrm{n}=315)$. Patients fulfilling the following inclusion criteria were eligible to be included in this study: (1) chronic secondary MR, (2) sinus rhythm, (3) narrow QRS interval ( $<120 \mathrm{~ms})$, and (4) measurable SPAP during exercise echocardiography. Of note, 19 patients $(6 \%)$ were excluded from the final analysis according to this last exclusion criterion, resulting in a feasibility rate in the measurement of exercise SPAP of $94 \%$. The final studied population was composed of 159 consecutive patients with heart failure (mean LV ejection fraction $36 \pm 7 \%$, range $20 \%$ to $44 \%$ ). All had been stable for $\geq 2$ months, and none met the following exclusion criteria (1) technically inadequate echocardiogram, (2) more than trivial aortic regurgitation or mild or greater aortic stenosis or severe tricuspid regurgitation, (3) history of myocardial infarction $<6$ months, (4) atrial fibrillation or flutter, (5) evidence of inducible ischemia, and (6) extensive myocardial ischemia requiring coronary angiography and revascularization. None of the patients were in New York Heart Association 

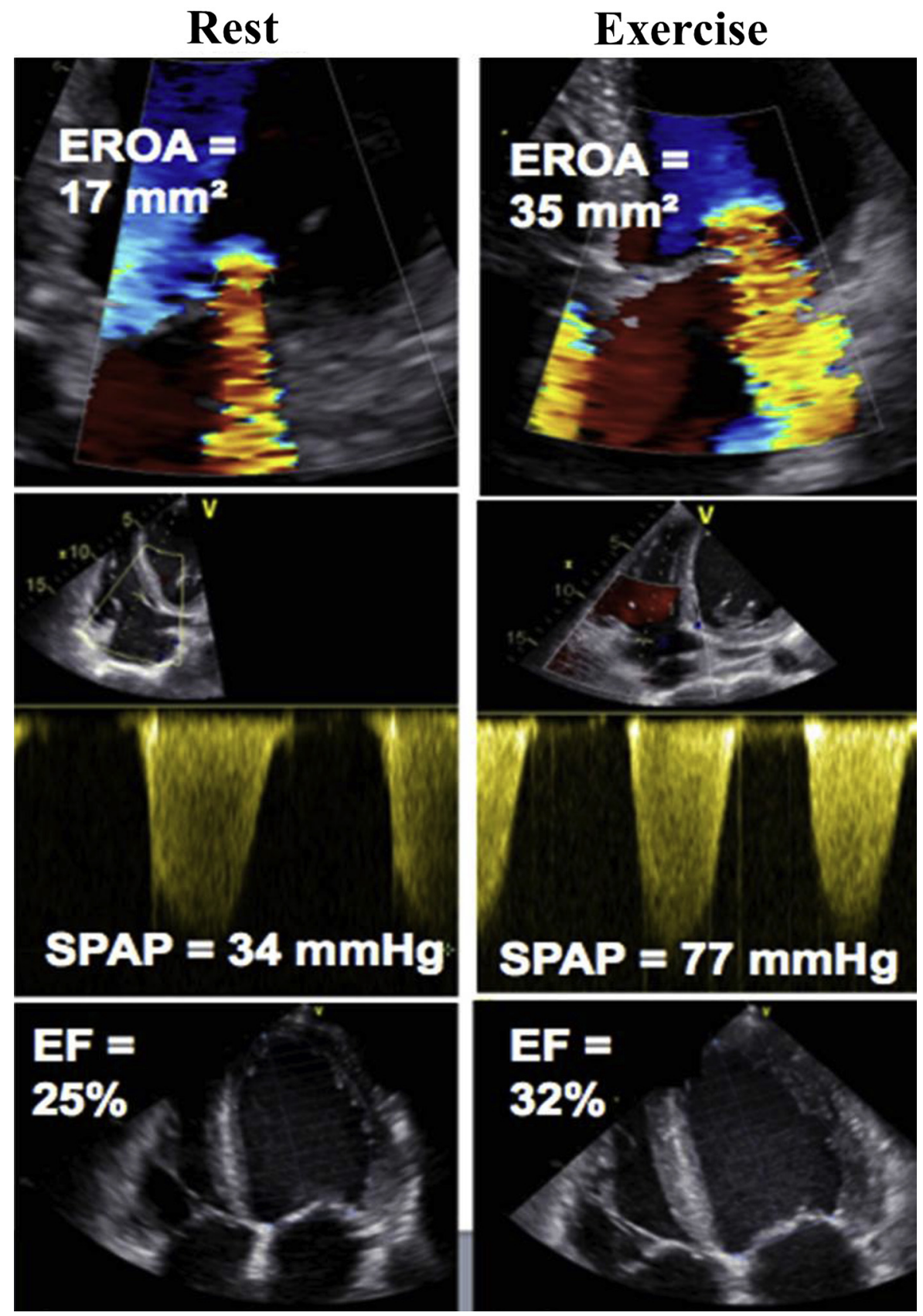

Figure 1. Exercise-induced increase in MR and in SPAP. EF = ejection fraction.

functional class IV. All patients gave their informed consent, and the local ethics committee approved the protocol.

The presence of hypercholesterolemia was defined as total plasma cholesterol level $>6.2 \mathrm{mmol} / \mathrm{L}$ or the use of cholesterol-lowering medications. Systemic hypertension was defined as the use of antihypertensive medications or having known but untreated hypertension (blood pressure $\geq 140 / 90 \mathrm{~mm} \mathrm{Hg}$ ).

All echocardiographic parameters were obtained at rest and at peak exercise in the same cycling semisupine position (Vivid 7 or 9; GE Healthcare, Little Chalfont, United Kingdom). All Doppler echocardiographic recordings were stored on a dedicated workstation for subsequent off-line analysis. For each measurement, $\geq 2$ cardiac cycles were averaged. MR was quantified as previously described ${ }^{6}$ (Figure 1). Regurgitant volume (RV) and effective regurgitant orifice area (EROA) area were calculated with standard formulas. The biplane method of discs summation (modified Simpson's rule) was applied to quantify LV enddiastolic and end-systolic volumes and the LV ejection fraction. From the mitral inflow, the E- and A-wave velocities, E-wave deceleration time, and E/A velocity ratio were measured. Left atrial maximal volume was measured using the modified Simpson's rule. Using color tissue Doppler imaging, peak velocities during early $\left(\mathrm{e}^{\prime}\right)$ diastole obtained at the level of septal and lateral annulus were averaged. The E/ $\mathrm{e}^{\prime}$ ratio was then calculated. SPAP was derived from the regurgitant jet of tricuspid regurgitation using the systolic 
Table 1

Demographic and clinical data

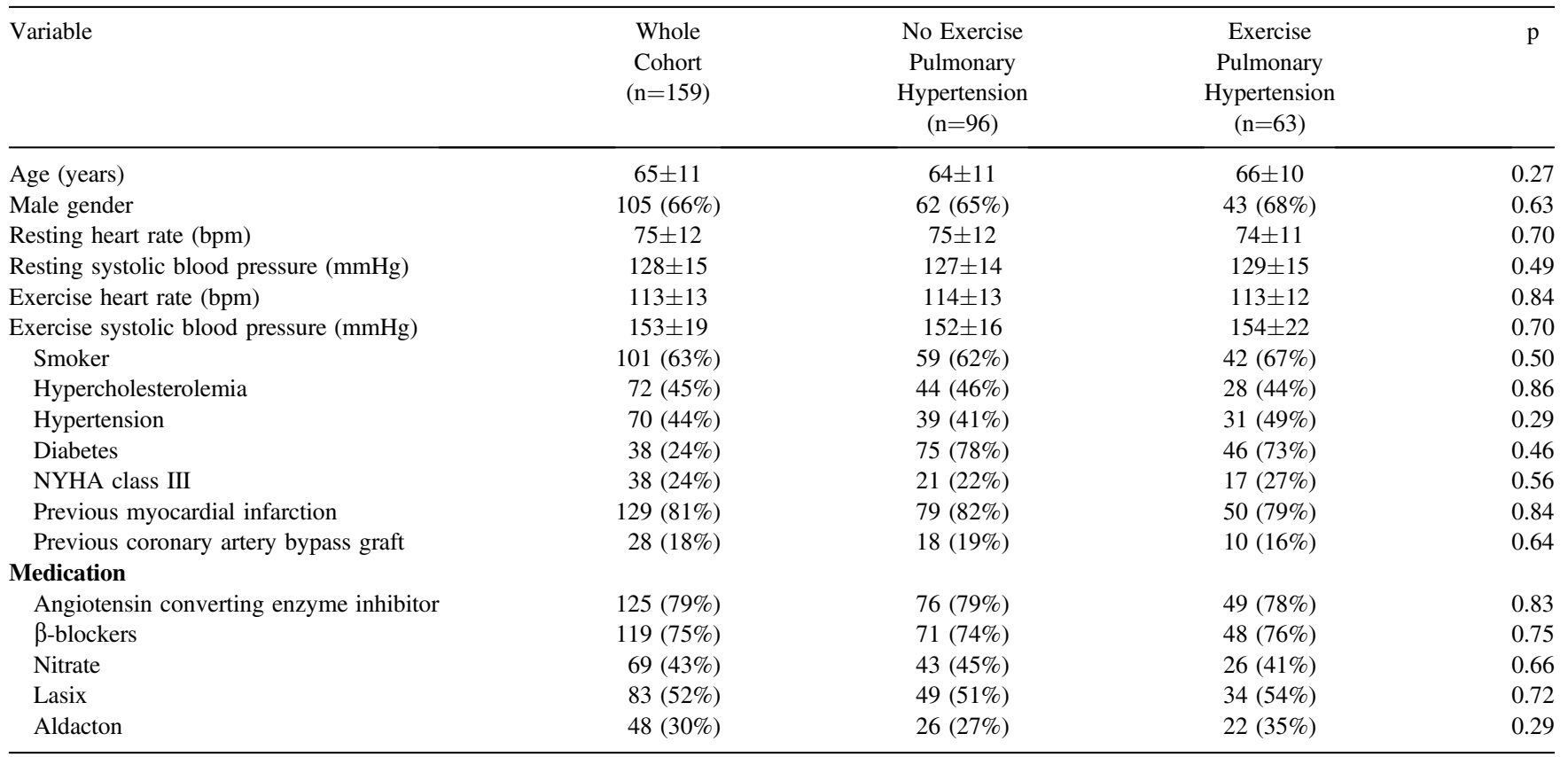

Table 2

Resting and echocardiographic data

\begin{tabular}{|c|c|c|c|c|}
\hline Variable & $\begin{array}{l}\text { Whole Cohort } \\
\qquad(\mathrm{n}=159)\end{array}$ & $\begin{array}{c}\text { No Exercise } \\
\text { Pulmonary } \\
\text { Hypertension } \\
(\mathrm{n}=96)\end{array}$ & $\begin{array}{c}\text { Exercise } \\
\text { Pulmonary } \\
\text { Hypertension } \\
(\mathrm{n}=63)\end{array}$ & $\mathrm{p}$ \\
\hline \multicolumn{5}{|l|}{ Resting Left ventricular and left atrial parameters } \\
\hline Left ventricular end-systolic volume (mL) & $93 \pm 25$ & $94 \pm 26$ & $92 \pm 22$ & 0.61 \\
\hline Left ventricular end-diastolic volume $(\mathrm{mL})$ & $144 \pm 30$ & $145 \pm 31$ & $143 \pm 28$ & 0.72 \\
\hline E-wave velocity $(\mathrm{cm} / \mathrm{s})$ & $69 \pm 24$ & $72 \pm 25$ & $65 \pm 22$ & 0.047 \\
\hline A-wave velocity $(\mathrm{cm} / \mathrm{s})$ & $62 \pm 27$ & $63 \pm 26$ & $60 \pm 28$ & 0.56 \\
\hline e'-wave velocity $(\mathrm{cm} / \mathrm{s})$ & $5.0 \pm 1.8$ & $5.5 \pm 1.8$ & $4.2 \pm 1.4$ & $<0.0001$ \\
\hline E/e' ratio & $15.2 \pm 6.8$ & $14.2 \pm 6.3$ & $16.7 \pm 7.3$ & 0.025 \\
\hline Left atrial area $\left(\mathrm{cm}^{2}\right)$ & $18.7 \pm 4.4$ & $18.8 \pm 4.7$ & $18.6 \pm 3.8$ & 0.78 \\
\hline \multicolumn{5}{|l|}{ Resting mitral regurgitation severity } \\
\hline Left ventricular end-systolic volume (mL) & $82 \pm 27$ & $82 \pm 29$ & $81 \pm 25$ & 0.71 \\
\hline Left ventricular end-diastolic volume (mL) & $143 \pm 32$ & $145 \pm 34$ & $140 \pm 29$ & 0.27 \\
\hline Left ventricular ejection fraction (\%) & $43 \pm 10$ & $44 \pm 9$ & $43 \pm 11$ & 0.46 \\
\hline Wall motion score index & $1.47 \pm 0.32$ & $1.47 \pm 0.31$ & $1.49 \pm 0.34$ & 0.73 \\
\hline E-wave velocity $(\mathrm{cm} / \mathrm{s})$ & $100 \pm 25$ & $99 \pm 24$ & $104 \pm 28$ & 0.24 \\
\hline A-wave velocity $(\mathrm{cm} / \mathrm{s})$ & $67 \pm 26$ & $71 \pm 27$ & $59 \pm 23$ & 0.12 \\
\hline e'-wave velocity $(\mathrm{cm} / \mathrm{s})$ & $6.3 \pm 2.3$ & $7.1 \pm 2.4$ & $5.1 \pm 1.5$ & $<0.0001$ \\
\hline $\mathrm{E} / \mathrm{e}^{\prime}$ ratio & $18 \pm 8.4$ & $15.7 \pm 8$ & $21.5 \pm 7.7$ & $<0.0001$ \\
\hline Left atrial area $\left(\mathrm{cm}^{2}\right)$ & $19.9 \pm 4.7$ & $19.7 \pm 4.7$ & $20.3 \pm 4.7$ & 0.46 \\
\hline \multicolumn{5}{|l|}{ Exercise mitral regurgitation severity } \\
\hline Effective regurgitant orifice area $\left(\mathrm{mm}^{2}\right)$ & $25 \pm 14$ & $21 \pm 11$ & $32 \pm 15$ & $<0.0001$ \\
\hline Regurgitant volume (mL) & $32 \pm 20$ & $27 \pm 19$ & $40 \pm 19$ & $<0.0001$ \\
\hline
\end{tabular}


Table 3

Relationship between exercise systolic pulmonary arterial pressure and resting and exercise echocardiographic data

\begin{tabular}{|c|c|c|}
\hline \multirow[t]{2}{*}{ Variable } & \multicolumn{2}{|c|}{$\begin{array}{c}\text { Exercise Systolic Pulmonary } \\
\text { Arterial Pressure }\end{array}$} \\
\hline & $\mathrm{r}$ & $\mathrm{p}$ \\
\hline \multicolumn{3}{|l|}{$\begin{array}{l}\text { Resting left ventricular and left } \\
\text { atrial parameters }\end{array}$} \\
\hline $\begin{array}{l}\text { Left ventricular end-systolic } \\
\text { volume }\end{array}$ & -0.01 & 0.91 \\
\hline $\begin{array}{l}\text { Left ventricular end-diastolic } \\
\text { volume }\end{array}$ & 0.01 & 0.93 \\
\hline Left ventricular ejection fraction & 0.03 & 0.67 \\
\hline Wall motion score index & -0.07 & 0.41 \\
\hline E-wave velocity & -0.10 & 0.20 \\
\hline A-wave velocity & -0.05 & 0.49 \\
\hline e'-wave velocity & -0.25 & 0.002 \\
\hline E/e' ratio & 0.13 & 0.10 \\
\hline Left atrial area & -0.05 & 0.57 \\
\hline \multicolumn{3}{|l|}{ Resting MR severity } \\
\hline Effective regurgitant orifice area & 0.16 & 0.84 \\
\hline Regurgitant volume & 0.08 & 0.34 \\
\hline $\begin{array}{l}\text { Resting systolic pulmonary arterial } \\
\text { pressure }\end{array}$ & 0.58 & $<0.0001$ \\
\hline \multicolumn{3}{|l|}{ Exercise $L V$ and LA parameters } \\
\hline $\begin{array}{l}\text { Left ventricular end-systolic } \\
\text { volume }\end{array}$ & -0.01 & 0.87 \\
\hline $\begin{array}{l}\text { Left ventricular end-diastolic } \\
\text { volume }\end{array}$ & -0.06 & 0.47 \\
\hline Left ventricular ejection fraction & -0.01 & 0.92 \\
\hline Wall motion score index & 0.04 & 0.62 \\
\hline E-wave velocity & 0.06 & 0.44 \\
\hline A-wave velocity & -0.02 & 0.91 \\
\hline e'-wave velocity & -0.31 & $<0.0001$ \\
\hline $\mathrm{E} / \mathrm{e}^{\prime}$ ratio & 0.26 & 0.001 \\
\hline Left atrial area & 0.04 & 0.67 \\
\hline \multicolumn{3}{|l|}{ Exercise MR severity } \\
\hline Effective regurgitant orifice area & 0.34 & $<0.0001$ \\
\hline Regurgitant volume & 0.31 & $<0.0001$ \\
\hline
\end{tabular}

transtricuspid pressure gradient (Figure 1) and the addition of $10 \mathrm{~mm} \mathrm{Hg}$ for right atrial pressure, as previously performed. ${ }^{1,2}$ Resting $\mathrm{PH}$ and exercise $\mathrm{PH}$ were defined as SPAP $>50$ and $>60 \mathrm{~mm} \mathrm{Hg}$, respectively. Right atrial pressure was assumed to be constant from rest to exercise.

Beta blockers were withdrawn on the day of the test. A symptom-limited graded bicycle exercise test was performed in the semisupine position on a tilting exercise table. After an initial workload of $25 \mathrm{~W}$ maintained for 2 minutes, the workload was increased every 2 minutes by $25 \mathrm{~W}$. Blood pressure and a 12-lead electrocardiogram were recorded every 2 minutes. Two-dimensional and Doppler echocardiographic recordings were available throughout the test.

Follow-up information was obtained from interviews with the patients, their relatives, or their physicians. Clinical management was determined independently by the patient's personal physician using all information available. The primary end point was cardiac mortality. The combined end point included the following: cardiac-related death, heart failure decompensation (worsening heart failure requiring hospitalization, acute pulmonary edema), need for cardiac resynchronization therapy or implantable cardiac defibrillator, or heart
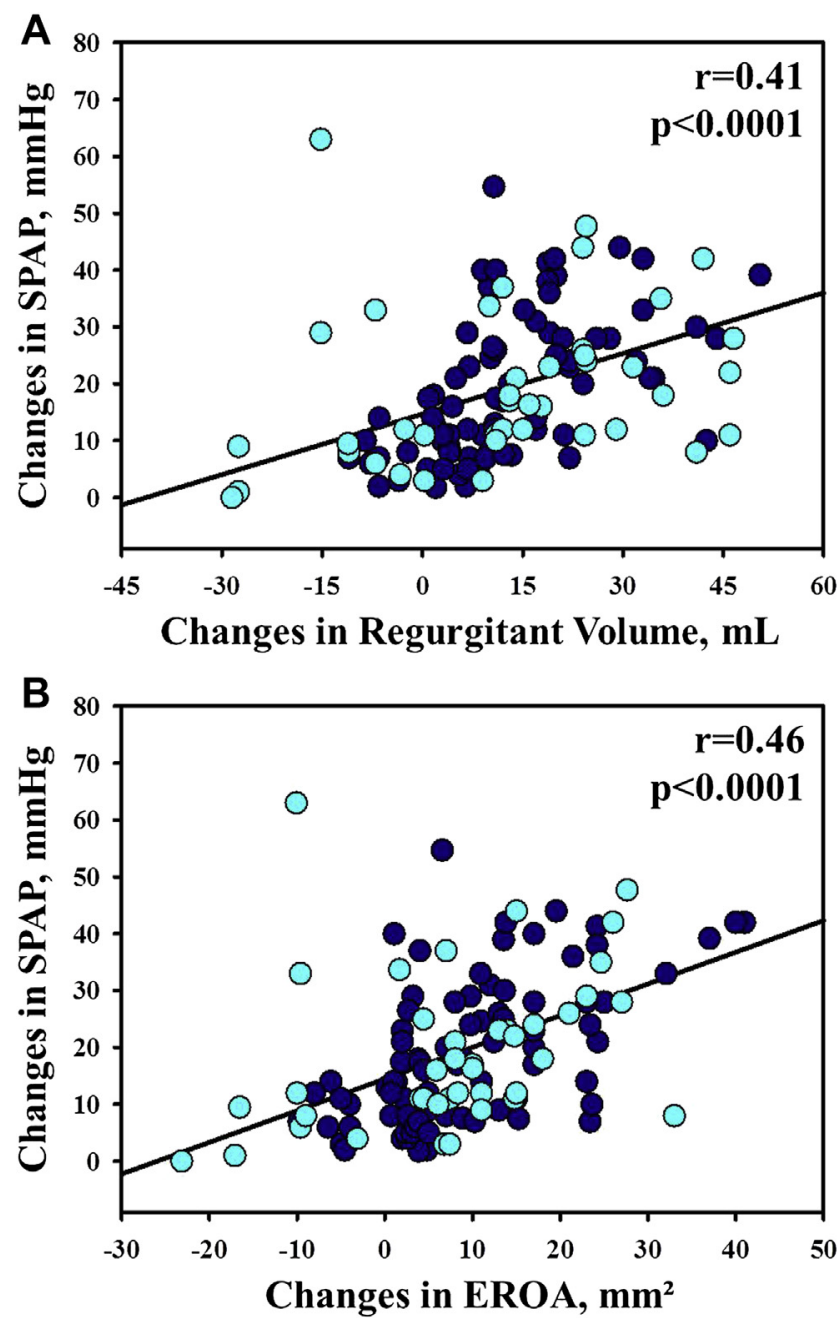

Figure 2. Relation between exercise-induced changes in SPAP and exercise-induced changes in RV $(A)$ and in EROA $(B)$, stratified according to resting MR severity (light blue dots denote resting EROA $>20 \mathrm{~mm}^{2}$; dark blue dots denote resting EROA $\leq 20 \mathrm{~mm}^{2}$ ).

transplantation. Nonfatal myocardial infarction was reported in the population with histories of ischemic heart disease but was not considered a PH-related event.

Continuous variables are expressed as mean $\pm \mathrm{SD}$, unless otherwise specified. Group comparisons for categorical variables were obtained with chi-square tests and for continuous variables with Student's $t$ tests. Probabilities of event-free survival were obtained by Kaplan-Meier estimates for the 2 groups and then compared using a 2-sided log-rank test. The impact of exercise $\mathrm{PH}$ on the occurrence of the end point was assessed with Cox proportional hazards models in univariate and multivariable analyses. Variables with a univariate $\mathrm{p}$ values $<0.10$ were incorporated into the multivariate models. We used penalized smoothing splines to illustrate the association of SPAP as a continuous variable and the risk for cardiac event. ${ }^{7}$ A $p$ value $<0.05$ was considered to indicate statistical significance.

\section{Results}

The demographic and clinical data of the 159 included patients are listed in Table 1. None of the patients, at the 
Table 4

Multivariable determinants of exercise systolic pulmonary arterial pressure

\begin{tabular}{|c|c|c|c|}
\hline \multirow[t]{2}{*}{ Variable } & \multicolumn{3}{|c|}{$\begin{array}{l}\text { Exercise systolic pulmonary } \\
\text { arterial pressure }\end{array}$} \\
\hline & $\beta$ & $\begin{array}{l}\text { Standard } \\
\text { error }\end{array}$ & $\mathrm{p}$ \\
\hline Age & 0.099 & 0.091 & 0.277 \\
\hline Male gender & 1.931 & 2.073 & 0.353 \\
\hline $\begin{array}{l}\text { Resting systolic pulmonary arterial } \\
\text { pressure }\end{array}$ & 0.947 & 0.096 & $<0.0001$ \\
\hline Exercise effective regurgitant orifice area & 0.578 & 0.089 & $<0.0001$ \\
\hline e'-wave velocity & -1.258 & 0.429 & 0.004 \\
\hline
\end{tabular}

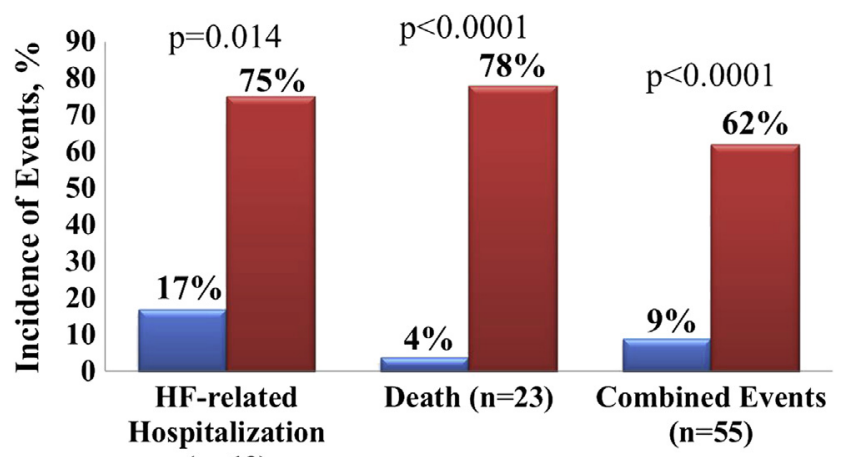

$(\mathrm{n}=12) \square$ Resting PHT Exercise PHT

Figure 3. Incidence of heart failure (HF) hospitalization, death, and combined cardiovascular events in patients with resting $\mathrm{PH}$ versus exercise $\mathrm{PH}$.

time of the study, had suspected significant coronary artery disease requiring myocardial revascularization. The prevalence of exercise $\mathrm{PH}$ was significantly higher than resting PH $(40 \%$ vs $13 \%, \mathrm{p}<0.0001)$. There was no significant difference between patients with exercise $\mathrm{PH}$ and those without exercise $\mathrm{PH}$ regarding demographic and clinical data, as well as baseline medication (Table 1).

In the whole cohort, SPAP significantly increased from rest to exercise $(+19 \pm 13 \mathrm{~mm} \mathrm{Hg}, \mathrm{p}<0.0001)$. Patients with exercise $\mathrm{PH}$ had statistically lower resting E- and $\mathrm{e}^{\prime}$-wave velocities but higher E/e' ratios (Table 2). Resting SPAP was significantly higher in the exercise $\mathrm{PH}$ group. Of note, there was no significant difference between the 2 groups regarding resting MR severity (Table 2). During exercise, $\mathrm{e}^{\prime}$-wave velocity was lower in exercise PH group compared with the no exercise $\mathrm{PH}$ group, resulting in significantly higher exercise $\mathrm{E} / \mathrm{e}^{\prime}$ ratios. During exercise, MR severity was available (i.e., quantifiable) in 120 patients (75\%); MR increased significantly in the whole cohort $\left(\right.$ EROA $+8.5 \pm 11 \mathrm{~mm}^{2}, \mathrm{p}<0.0001$, and $\mathrm{RV}+12 \pm 15 \mathrm{ml}$, $\mathrm{p}<0.0001$ ). Exercise (Table 2) and exercise-induced increase in MR severity were significantly higher in patients with exercise $\mathrm{PH}$ than in those with no exercise $\mathrm{PH}$ $\left(\right.$ EROA $+14 \pm 11 \mathrm{vs}+5 \pm 10 \mathrm{~mm}^{2}, \mathrm{p}<0.0001$, and $\mathrm{RV}+19 \pm 16$ vs $+8 \pm 14 \mathrm{ml}, \mathrm{p}<0.0001)$.

In simple linear regression, exercise SPAP was significantly correlated (Table 3 ) with resting and exercise e ${ }^{\prime}$-wave velocity, resting SPAP, exercise $\mathrm{E} / \mathrm{e}^{\prime}$ ratio, and exercise EROA and RV. Of note, exercise-induced changes in SPAP were well correlated with exercise-induced changes in RV

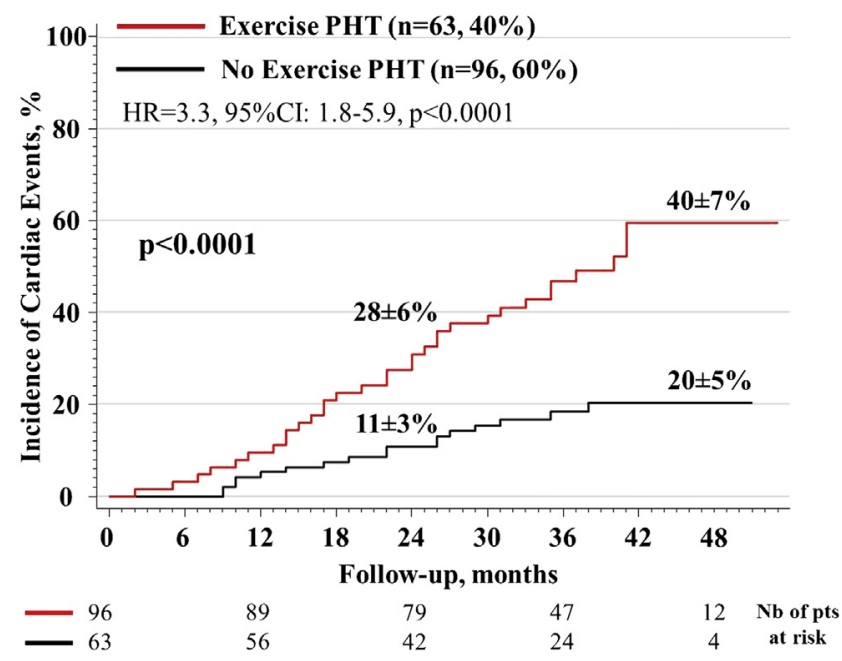

Figure 4. Incidence of combined cardiac events according to the presence or not of exercise PH. Percentages reported in the graphs are the rates of events at 2- and 4-year follow-up.

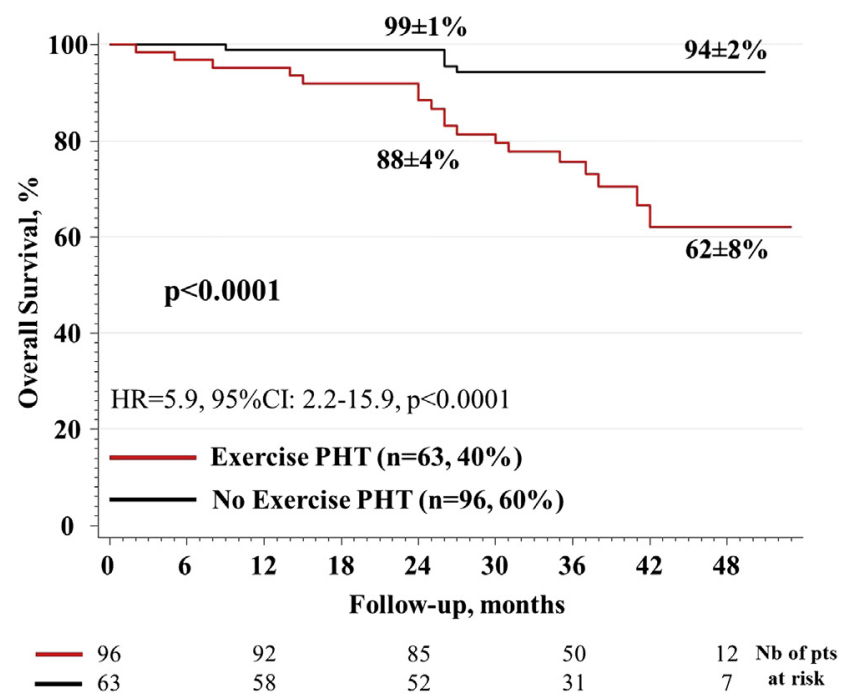

Figure 5. Overall survival according to the presence or not of exercise PH. Percentages reported in the graphs are the rates of survival at 2- and 4-year follow-up.

and in EROA (Figure 2) Using multiple linear regression analysis, resting SPAP, exercise EROA, and $\mathrm{e}^{\prime}$-wave velocity were identified as independent determinants of exercise SPAP (Table 4). Similar results were found when exercise RV was included in the model instead of exercise EROA $(\beta=0.26 \pm 0.05, \mathrm{p}<0.0001)$.

During a mean follow-up period of $35 \pm 11$ months (range 2 to 53), 38 patients experienced heart failure decompensation, 6 underwent cardiac resynchronization therapy or implantable cardiac defibrillator placement, 1 underwent heart transplantation, 12 had recurrent myocardial infarctions, and 23 died of cardiac causes. In the whole cohort, the survival rates were $95 \pm 2 \%$ and $81 \pm 4 \%$ at 2 and 4 years, and the rates of cardiac events were $19 \pm 3 \%$ and $37 \pm 5 \%$. The rates of combined events were not different between patients with and those without resting $\mathrm{PH}$ $(24 \%$ vs $36 \%, \mathrm{p}=0.19)$, whereas exercise $\mathrm{PH}$ was 
Table 5

Cox proportional Hazard model: determinant of death, heart failure hospitalization and combined cardiac event

\begin{tabular}{|c|c|c|c|c|c|c|c|c|c|}
\hline \multirow[t]{2}{*}{ Variable } & \multicolumn{3}{|c|}{ Model\#1: Heart failure hospitalization } & \multicolumn{3}{|c|}{ Model\#2: Death } & \multicolumn{3}{|c|}{ Model\#3: Cardiac event } \\
\hline & HR & $95 \% \mathrm{CI}$ & $\mathrm{p}$ & HR & $95 \% \mathrm{CI}$ & $\mathrm{p}$ & HR & $95 \% \mathrm{CI}$ & $\mathrm{p}$ \\
\hline Age & 0.991 & $0.957-1.026$ & 0.600 & 1.015 & $0.974-1.057$ & 0.481 & 1.008 & $0.981-1.035$ & 0.568 \\
\hline Gender & 0.783 & $0.300-2.046$ & 0.618 & 0.883 & $0.328-2.373$ & 0.805 & 0.870 & $0.450-1.684$ & 0.680 \\
\hline Left ventricular end-systolic volume & 1.021 & $0.982-1.062$ & 0.294 & 0.990 & $0.948-1.034$ & 0.654 & 0.994 & $0.965-1.023$ & 0.662 \\
\hline Left ventricular end-diastolic volume & 1.006 & $0.973-1.040$ & 0.735 & 1.020 & $0.984-1.057$ & 0.286 & 1.026 & $1.002-1.051$ & 0.037 \\
\hline e'-wave velocity & 1.191 & $0.900-1.576$ & 0.222 & 0.890 & $0.646-1.227$ & 0.478 & 1.052 & $0.857-1.291$ & 0.627 \\
\hline Exercise E/e' ratio & 1.040 & $0.987-1.096$ & 0.140 & 0.987 & $0.931-1.046$ & 0.656 & 1.026 & $0.987-1.066$ & 0.188 \\
\hline Resting effective regurgitant orifice area & 1.001 & $0.962-1.042$ & 0.945 & 1.035 & $0.992-1.081$ & 0.111 & 1.011 & $0.982-1.040$ & 0.463 \\
\hline Exercise pulmonary hypertension & 3.770 & $1.517-9.370$ & 0.004 & 5.337 & $1.754-16.242$ & 0.003 & 3.691 & $1.878-7.252$ & $<0.0001$ \\
\hline
\end{tabular}

$\mathrm{CI}=$ confidence interval; $\mathrm{HR}=$ hazard ratio.

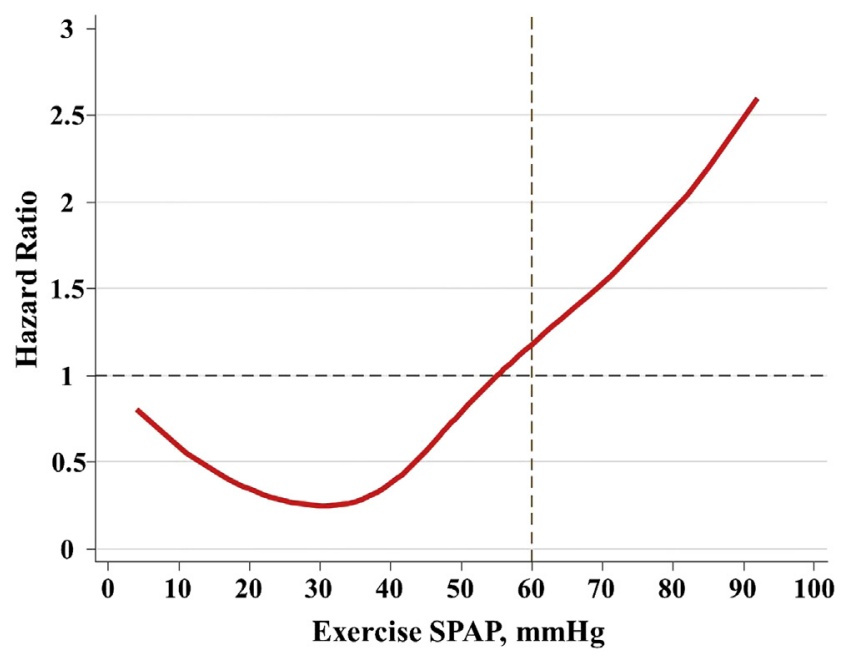

Figure 6. Association between exercise SPAP and the overall mortality risk. HRs (solid line) were estimated in a Cox univariate model.

significantly associated with a higher rate $(62 \%$ vs $38 \%$, p $<0.0001)$. In addition, patients with exercise $\mathrm{PH}$ exhibited higher rates of cardiac events and death than those with resting PH (Figure 3). The incidence of cardiac events during follow-up was significantly higher in patients with exercise PH compared with those without exercise PH (Figure 4). Similarly, patients with exercise $\mathrm{PH}$ demonstrated significantly reduced survival (Figure 5). Kaplan-Meier curve analysis showed that resting PH was not significantly associated with cardiac-related death $(\mathrm{p}=0.12)$, heart failure decompensation $(\mathrm{p}=0.09)$, or combined events $(\mathrm{p}=0.052)$. This lack of statistical significance was even more pronounced after adjustment of age and gender.

In contrast, in a multivariate Cox proportional hazards model, after adjustment for age and gender, exercise PH was associated with heart failure decompensation, cardiac-related death, or any combined cardiac event (hazard ratio [HR] 2.9, $95 \%$ confidence interval $[\mathrm{CI}] 1.3$ to $6.5, \mathrm{p}=0.009$; HR 5.7, $95 \% \mathrm{CI} 2.1$ to $15.5, \mathrm{p}=0.001$; and HR $3.2,95 \% \mathrm{CI} 1.8$ to $5.9, \mathrm{p}<0.0001$, respectively). Using further adjustment for LV volumes, resting and exercise diastolic function, and resting MR severity, exercise $\mathrm{PH}$ remained systematically associated with higher risk for event or death (Table 5). In this final model, the addition of exercise EROA led to similar results with an independent association between exercise $\mathrm{PH}$ and the combined end point (HR 2.05, 95\% CI 1.03 to 4.05, $\mathrm{p}=0.04)$. The relation between exercise SPAP and the risk for combined cardiac events was assessed using the spline function (Figure 6). The previous suggested threshold of exercise SPAP $>60 \mathrm{~mm} \mathrm{Hg}$ to define $\mathrm{PH}$ was confirmed in the present cohort of patients with secondary MR (Figure 6). The risk for cardiac events during follow-up increased exponentially with the level of exercise SPAP, becoming significant at $>60 \mathrm{~mm} \mathrm{Hg}$. Beyond $70 \mathrm{~mm} \mathrm{Hg}(\mathrm{n}=7)$ and $80 \mathrm{~mm} \mathrm{Hg}(\mathrm{n}=5)$, the risk for events increased by $50 \%$ (HR from 1 to 1.5 ) and $100 \%$ (HR from 1 to 2), respectively. In patients with resting EROA $<20 \mathrm{~mm}^{2}(\mathrm{n}=110)$, exercise $\mathrm{PH}$ was significantly associated with increased occurrence of heart failure decompensation $(\mathrm{p}=0.025)$, rate of cardiovascular events $(\mathrm{p}=0.003)$, and reduced survival $(\mathrm{p}=0.015)$ compared with patients without exercise PH.

\section{Discussion}

The results of our study show that exercise PH (1) is frequent $(40 \%)$ in patients with secondary MR, narrow QRS intervals, and severe LV systolic dysfunction; (2) is determined mainly by resting SPAP and $\mathrm{e}^{\prime}$-wave velocity, as well as exercise EROA; and (3) is a powerful predictor of the occurrence of heart failure decompensation, cardiac-related death, or combined cardiovascular events.

Exercise PH (40\%) was significantly more frequent than resting $\mathrm{PH}(13 \%)$ in our population. As in other studies, we showed that exercise $\mathrm{PH}$ was related mostly to exercise valvular lesion severity (i.e., MR severity) and LV filling pressure and/or LV diastolic burden but not to New York Heart Association class. Although these parameters were highly predictive of $\mathrm{PH}$, exercise $\mathrm{PH}$ emerged as a distinct risk factor for major cardiovascular events. Therefore, as in other valvular heart diseases, exercise $\mathrm{PH}$ can potentially identify a subset of patients who are at higher risk. $1,2,8,9$

In secondary MR, the dynamic increase in MR is a major determinant of the exercise augmentation in SPAP and of exercise $\mathrm{PH}^{3,10}$; it is also involved in the pathogenesis of acute pulmonary edema irrespective of $\mathrm{LV}$ function. ${ }^{11}$ During exercise, the abrupt increase in MR severity, even if mild, may exceed the level of left atrial compliance and pulmonary vascular recruitment and leads to a significant increase in SPAP up to PH. Although initially benign, such a phenomenon, when repetitive, can gradually proceed to 
left atrial dilatation, increased LV filling pressure, atrial fibrillation, right ventricular dysfunction, low-level exercise dyspnea, and finally resting symptoms. ${ }^{12}$

Although prognostically robust, measurement of SPAP at peak exercise weakly reflects the dynamic and kinetic changes in pulmonary vascular resistance during exercise. Lewis et al, ${ }^{1,14}$ using multipoint SPAP-flow plots, showed that patients with heart failure exhibiting a steeper slope or depicting a "plateau" pattern-a steep increase in SPAP at low workload followed by a flat slope at higher exercise load-had worse outcomes. However, this approach appears less feasible in daily routine practice than the straightforward measurement of SPAP at peak exercise.

In our experience, exercise SPAP is a much more reproducible and feasible parameters than exercise MR severity. In this regard, we do not recommend systematically quantifying MR severity during exercise ${ }^{15,16}$ but rather exercise SPAP. In addition, the relation between exercise SPAP and maximal exercise capacity or respiratory gas exchange analysis would be of great interest and still requires further investigation.

The management of patients with chronic secondary MR remains challenging. Although current guidelines advocates mitral valve surgery in patients with severe secondary MR at the time of coronary artery bypass grafting, ${ }^{5,17}$ mitral valve repair does not represent a unanimous therapeutic option for chronic moderate secondary MR. As suggested in the European Society of Cardiology guidelines, exercise PH may represent a further incentive for combined surgery. However, to date, data supporting such a recommendation are still lacking.

Our results confirm the deleterious effects of exercise $\mathrm{PH}$ in patients with LV systolic dysfunction and secondary MR. Exercise PH negatively influences the outcome irrespective of the degree of secondary MR. It is associated with a 3.7fold increased risk for combined cardiac events and a 5.3-fold increased risk for cardiac-related death during follow-up. Conversely, the lack of exercise PH confers a good prognosis, with cardiac event rates of $91 \pm 3.5 \%$ at 2 years and $84 \pm 5 \%$ at 4 years. Therefore, the presence of elevated exercise SPAP can unmask a subset of patients who may benefit from targeted therapeutic approaches. When surgical revascularization is contemplated, combined mitral valve repair might be beneficial. For the other clinical conditions, close monitoring, if possible in a heart valve clinic, ${ }^{18}$ and strict adherence to treatment guidelines for heart failure are recommended.

Right atrial pressure was estimated at $10 \mathrm{~mm} \mathrm{Hg}$ at rest and during exercise. Resting right atrial pressure is extensively variable among subjects. In addition, this estimation may also miss the potential influence of exercise-induced changes in right atrial pressure. Nevertheless, the noninvasive evaluation of right atrial pressure during exercise (i.e., when venous compliance is known to decrease) with noninvasive methods such as Doppler echocardiography remains difficult, is probably subject to low accuracy, and is not validated. Moreover, right atrial pressure is frequently assumed to be $5 \mathrm{~mm} \mathrm{Hg}$ in normal subjects ${ }^{19}$ and $10 \mathrm{~mm} \mathrm{Hg}$ in patients with heart disease. ${ }^{20}$ The calculation of multipoint slope of the SPAP-flow plots during exercise was not performed. However, it is a very demanding approach to assess the pulmonary vascular adaptation to exercise. The use of a 2-point SPAP-flow slope presents inherent methodologic limitations.

\section{Disclosures}

The authors have no conflicts of interest to disclose.

1. Magne J, Lancellotti P, Pierard LA. Exercise pulmonary hypertension in asymptomatic degenerative mitral regurgitation. Circulation 2010;122:33-41.

2. Lancellotti P, Magne J, Donal E, O’Connor K, Dulgheru R, Rosca M, Pierard LA. Determinants and prognostic significance of exercise pulmonary hypertension in asymptomatic severe aortic stenosis. Circulation 2012;126:851-859.

3. Tumminello G, Lancellotti P, Lempereur M, D'Orio V, Pierard LA. Determinants of pulmonary artery hypertension at rest and during exercise in patients with heart failure. Eur Heart J 2007;28:569-574.

4. Pierard LA, Lancellotti P. The role of ischemic mitral regurgitation in the pathogenesis of acute pulmonary edema. $N$ Engl J Med 2004;351: $1627-1634$

5. Vahanian A, Alfieri O, Andreotti F, Antunes MJ, Barón-Esquivias G, Baumgartner H, Borger MA, Carrel TP, De Bonis M, Evangelista A, Falk V, Iung B, Lancellotti P, Pierard L, Price S, Schäfers HJ, Schuler G, Stepinska J, Swedberg K, Takkenberg J, Von Oppell UO, Windecker S, Zamorano JL, Zembala M. Guidelines on the management of valvular heart disease (version 2012): the Joint Task Force on the Management of Valvular Heart Disease of the European Society of Cardiology (ESC) and the European Association for Cardio-Thoracic Surgery (EACTS). Eur Heart J 2012;33: $2451-2496$

6. Lebrun F, Lancellotti P, Pierard LA. Quantitation of functional mitral regurgitation during bicycle exercise in patients with heart failure. $J \mathrm{Am}$ Coll Cardiol 2001;38:1685-1692.

7. Eilers PH, Marx BD. Flexible smoothing with B-splines and penalties. Stat Sci 1996;11:89-121.

8. Brochet E, Detaint D, Fondard O, Tazi-Mezalek A, Messika-Zeitoun D, Iung B, Vahanian A. Early hemodynamic changes versus peak values: what is more useful to predict occurrence of dyspnea during stress echocardiography in patients with asymptomatic mitral stenosis? J Am Soc Echocardiogr 2011;24:392-398.

9. Kusunose K, Popovic ZB, Motoki H, Marwick TH. Prognostic significance of exercise induced right ventricular dysfunction in asymptomatic degenerative mitral regurgitation. Circ Cardiovasc Imaging 2013;6:167-176.

10. Magne J, Lancellotti P, Pierard LA. Exercise-induced changes in degenerative mitral regurgitation. J Am Coll Cardiol 2010;56: 300-309.

11. Ennezat PV, Marechaux S, Bouabdallaoui N, Le Jemtel TH. Dynamic nature of pulmonary artery systolic pressure in decompensated heart failure with preserved ejection fraction: role of functional mitral regurgitation. J Card Fail 2013;19:746-752.

12. Lewis GD, Bossone E, Naeije R, Grünig E, Saggar R, Lancellotti P, Ghio S, Varga J, Rajagopalan S, Oudiz R, Rubenfire M. Pulmonary vascular hemodynamic response to exercise in cardiopulmonary diseases. Circulation 2013;128:1470-1479.

13. Lewis GD, Murphy RM, Shah RV, Grünig E, Saggar R, Lancellotti P, Ghio S, Varga J, Rajagopalan S, Oudiz R, Rubenfire M. Pulmonary vascular response patterns during exercise in left ventricular systolic dysfunction predict exercise capacity and outcomes. Circ Heart Fail $2011 ; 4: 276-285$.

14. Tolle JJ, Waxman AB, Van Horn TL, Pappagianopoulos PP, Systrom DM. Exercise-induced pulmonary arterial hypertension. Circulation 2008;118:2183-2189.

15. Magne J, Lancellotti P, Pierard LA. Exercise testing in asymptomatic severe aortic stenosis. JACC Cardiovasc Imaging 2014;7:188-199.

16. Lancellotti P, Magne J. Stress echocardiography in regurgitant valve disease. Circ Cardiovasc Imaging 2013;6:840-849.

17. Nishimura RA, Otto CM, Bonow RO, Carabello BA, Erwin JP III, Guyton RA, O'Gara PT, Ruiz CE, Skubas NJ, Sorajja P, Sundt TM III, Thomas JD; ACC/AHA Task Force Members. 2014 AHA/ACC guideline for the management of patients with valvular heart disease: a Report of the American College of Cardiology/American heart 
The American Journal of Cardiology (www.ajconline.org)

association Task Force on Practice guidelines. Circulation 2014;129: 2440-2492.

18. Lancellotti P, Rosenhek R, Pibarot P, Iung B, Otto CM, Tornos P, Donal E, Prendergast B, Magne J, La Canna G, Piérard LA, Maurer G. ESC Working Group on Valvular Heart Disease position paper-heart valve clinics: organization, structure, and experiences. Eur Heart J 2013;34:1597-1606.
19. Mahjoub H, Levy F, Cassol M, Meimoun P, Peltier M, Rusinaru D, Tribouilloy C. Effects of age on pulmonary artery systolic pressure at rest and during exercise in normal adults. Eur J Echocardiogr 2009;10:635-640.

20. Schwammenthal E, Vered Z, Agranat O, Kaplinsky E, Rabinowitz B, Feinberg MS. Impact of atrioventricular compliance on pulmonary artery pressure in mitral stenosis: an exercise echocardiographic study. Circulation 2000;102:2378-2384. 